\title{
A PROPÓSITO DEL CAMINANTE
}

\section{ABOUT THE WALKER}

\section{(iD) Adolfo Quispe Arroyo ${ }^{*}$}

adolfiss@hotmail.com

${ }^{1}$ Universidad Nacional de San Cristóbal de Huamanga, Ayacucho, Perú

\section{*Correspondencia: Adolfo Quispe Arroyo. Email: adolfiss@hotmail.com}

Puriq (caminante) promueve la reflexión crítica sobre diversos estudios científicos de humanidades. En el camino o en la dinámica del conocimiento se enraman el producto de las investigaciones desde diferentes paradigmas y enfoques de temas pedagógicos, éticos, políticos entre otros. Caminar implica dinámica, movimiento como un motor de la historia y del desarrollo en general con proyección al futuro, previo análisis del presente. Caminante es la traducción española de puriq de raíz quechua de esta parte del Perú (Ayacucho).

El movimiento es la base del desarrollo de la realidad sea natural social o de pensamiento, puesto que es imposible considerar la realidad al margen del movimiento. En Puriq se describen y se explican los procesos que implican el desarrollo como una forma de la existencia de la realidad, ya que con ella nos acercamos, previa investigación, a los fenómenos naturales, sociales y psicológicos. El movimiento como manifestación del caminante genera la vida misma, simple y compleja a la vez, puesto que con la vida aspiramos acercarnos a la realidad sistematizando el conocimiento desde la antigüedad hasta nuestros días. Para sistematizar nuestros logros tuvimos que aprender a observar el fenómeno u objeto y no solamente mirar, tuvimos que afinar nuestros sentidos y nuestra racionalidad para dar forma a esa conciencia social superior llamada ciencia.

Tuvimos que ingeniarse y dar utilidad al arco y la flecha en la dinámica de la supervivencia para finalmente inspirar la construcción de los grandes cohetes espaciales; así como hábitos y formas de sobrevivencia en hordas nómades a los inicios y en grupos sedentarios posteriormente. La descripción y explicación de los fenómenos naturales, sociales y psicológicos se sistematizan en la ciencia tratados meticulosamente por diversos investigadores en una determinada disciplina científica propia o afín a su formación profesional y a su cultura investigativa.

La ciencia no es buena ni mala en sus características, es decir no puede ser sometida a un juicio ético, porque es simplemente un conjunto de conocimientos sistematizados que se dan en un determinado tiempo, pero la aplicación de estos conocimientos puede ser con fines malévolos o de perjuicio a la naturaleza o la sociedad y no necesariamente para provecho y felicidad de la humanidad y el equilibrio de la naturaleza. El hombre por utilizar el conocimiento de una forma o de otra puede ser sometido a un juicio ético, concluyendo este juicio como bueno o malo. Vale resaltar que se trata del hombre y no es un juicio a la ciencia, porque como señalamos, el conjunto de conocimientos se manifestará tarde o temprano al margen de las voluntades de los hombres de una determinada época. 
Un ejemplo típico es el caso de la edad media donde institucionalmente intentaron ocultar y prohibir la investigación que terminó en un fracaso histórico. Por este fiasco conocemos a esa etapa como la etapa o edad del oscurantismo por no decir de la ignorancia. Sabemos por historia que el hombre renace, se moderniza y acelera en la adquisición de conocimientos científicos y en la actualidad se socializan esas investigaciones cuyos códigos para la comunidad científica se encuentran en las publicaciones periódicas como el caminante de castilla o por el Puriq andino con razón operacional en la Universidad Nacional Autónoma de Huanta.

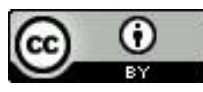

CITAR COMO:

Quispe Arroyo, A. (2021). A propósito del caminante. Puriq, 3(4), 435-436. https://doi.org/10.37073/puriq.3.4.254 